\title{
HOW TO WRITE A CONTRACT WITH THE AHP
}

\begin{abstract}
In this paper we show how the Analytic Hierarchy Process could be used to develop a legal contract in the process of a negotiation. We illustrate the process with a wellknown case used routinely in negotiation courses. We show that the AHP is particularly well suited for this type of applications where most of the dimensions and criteria are intangibles, and the scales used to measure the gains and costs of parties involved in the negotiation do not always exist.
\end{abstract}

Keywords: Negotiation, gain and loss ratios, value claim, value creation

\section{Introduction}

The dictionary definition of "contract" is "a binding agreement between two or more persons or parties" or "a document describing the terms of a contract." This implies that a contract has multiple dimensions and the parties must agree on each of the dimensions. For example, in the case of a recruiter trying to hire a candidate for a position in a company, the dimensions could be the signing bonus, salary, job assignment, company car, starting date, number of vacation days, percentage of moving expenses covered, the type of insurance coverage offered, and so on. Each dimension has a different impact on the parties.

There are two types of outcome at work when two parties negotiate: Value claim, and Value creation (see Figure 1).

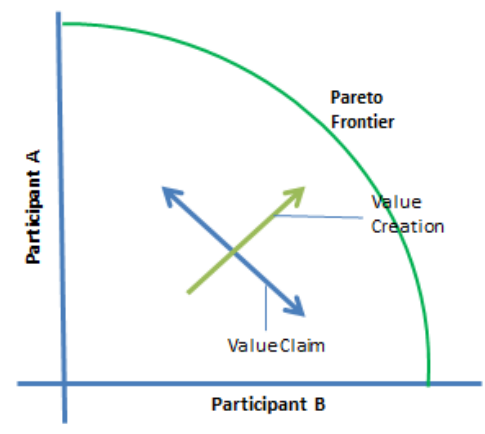

Figure 1. Value Claims, Value Creation and the Pareto Frontier 
Value claim occurs when one party is able to capture value from the other party during the negotiation process. This is most prevalent among those dimensions of the negotiation that are distributive (i.e., what one party gains, the other party experiences as a comparable loss). However, it can also manifest itself for integrative elements (i.e., when multiple factors are negotiated - some of which are more important to one of the parties, and some of which are more important to the other party). However, for both integrative and compatible dimensions (i.e., factors where the same element is perceived as a gain for both parties), there are also opportunities for exchange that leads to value creation. Thus, value creation takes place when both parties are made better off during the negotiation. When value creation occurs, the parties move closer towards the Pareto frontier - the point at which neither party can be made better off without the counterparty being made worse off.

\section{A Simple Example}

We mentioned above that a contract has multiple dimensions and the parties must agree on each of the dimensions. Thus, a negotiation to arrive a mutually agreed contract needs to consider the gains and losses of the parties in each of the dimensions. For example, a recruiter is negotiating with a prospective employee for a position. They need to agree on the conditions of employment. The negotiation involves agreement on a number of dimensions. Each dimension can be considered a benefit or a cost. Table 1 shows an example of dimensions of a negotiation and their type.

Table 1. Dimensions and their type

\begin{tabular}{|l|l|}
\hline Dimensions & Type \\
\hline SIGNING BONUS (SB) & Benefit \\
\hline SALARY (S) & Cost \\
\hline JOB ASSIGNMENT (JA) & Cost \\
\hline COMPANY CAR $($ CC) & Benefit \\
\hline STARTING DATE(SD) & Benefit \\
\hline VACATION DAYS (VD) & Benefit \\
\hline MOVING EXPENSES REIMB (MER) & Benefit \\
\hline INSURANCE COVERAGE(IC) & Benefit \\
\hline
\end{tabular}

In addition, within each type, the dimensions are not equally important. Table 2 shows the importance of the dimensions from both, the recruiter's and the employee's perspective. 
IS AHP How to write a contact with the AHP. To be submitted to the International Symposium of the Analytic Hierarchy Process, 2016, London U.K.

To develop the contract, the parties need to agree the level at which each of the dimensions must be set. Let us assume that the dimensions have intensities as in Table 3, and that each of those alternative intensities accrues a benefit or a cost, also given in Table 3.

Table 2. Recruiter/Employee Priorities for Benefits and Costs

\begin{tabular}{|l|c|c|}
\cline { 2 - 3 } \multicolumn{1}{c|}{} & \multicolumn{2}{c|}{ Priorities } \\
\hline Benefits & Recruiter & Employee \\
\hline SIGNING BONUS (SB) & 0.270 & 0.270 \\
\hline COMPANY CAR (CC) & 0.081 & 0.081 \\
\hline STARTING DATE (SD) & 0.108 & 0.270 \\
\hline VACATION DAYS (VD) & 0.270 & 0.108 \\
\hline MOVING EXPENSES (MER) & 0.054 & 0.216 \\
\hline INSURANCE COVERAGE(IC) & 0.216 & 0.054 \\
\hline & \multicolumn{2}{|c|}{ Priorities } \\
\hline Costs & Recruiter & Employee \\
\hline SALARY (S) & 0.75 & 0.75 \\
\hline JOB ASSIGNMENT (JA) & 0.25 & 0.25 \\
\hline
\end{tabular}

In many real life contract negotiations, neither the dimensions of the contract nor the intensity scales may be known. To make tradeoffs we need to identify the dimensions and the intensity scales. The intensity scales in Table 3 are expressed in relative terms in Table 4. The priorities of the dimensions are obtained by normalizing the sum total of each scale (see Table 4). In this example the scale values are all equispaced, i.e., they form a linear scale. However, in practice these values would be obtained through prioritization and they do not need to be linear.

The negotiation process consists in finding out what value each dimension should take for the recruiter and the candidate so that the total amount they get (benefit/cost ratio) is maximized satisfying the constraint that neither party gets more than the other, i.e, the contract is fair and equitable (Fisher and Ury 1981).

\section{The Trading Model}

To find the solution of this problem we model it with integer programming. A solution is represented by an 8-by-5 matrix $\left(x_{i j}\right)$ of 0 's and 1's. Each row corresponds to a dimension and each column corresponds to an intensity of the scale corresponding to that dimension. $x_{i j}=1$ if the $\mathrm{i}^{\text {th }}$ dimensions takes the $\mathrm{j}^{\text {th }}$ intensity value. Let $b_{i j}^{R}\left(b_{i j}^{C}\right)$ and 
IS AHP How to write a contact with the AHP. To be submitted to the International Symposium of the Analytic Hierarchy Process, 2016, London U.K.

$c_{i j}^{R}\left(c_{i j}^{C}\right)$ the benefit and cost corresponding to the $\mathrm{j}^{\text {th }}$ intensity of the $\mathrm{i}^{\text {th }}$ dimension for the recruiter (candidate).

The benefits/costs ratios of the recruiter and the candidate are given by

$$
r_{R}(x)=\frac{\text { benefits }}{\operatorname{costs}}=\frac{\sum_{i} w_{i}^{R} \sum_{j} x_{i j} b_{i j}^{R}}{\sum_{i} v_{i}^{R} \sum_{j} x_{i j} c_{i j}^{R}} \text { and } r_{C}(x)=\frac{\text { benefits }}{\operatorname{costs}}=\frac{\sum_{i} w_{i}^{C} \sum_{j} x_{i j} b_{i j}^{C}}{\sum_{i} v_{i}^{C} \sum_{j} x_{i j} c_{i j}^{C}},
$$

respectively.

The objective is to find a solution $x *$ such that the parties gain as much as possible,

$$
r_{R}\left(x^{*}\right)=r_{C}\left(x^{*}\right)=\underset{x \in X_{S}}{\operatorname{Max}}\left\{\operatorname{Min}\left\{r_{A}(x), r_{B}(x)\right\}\right\},
$$

where $X_{S}$ is the solution space defined as the set of matrices $\left(x_{i j}\right)$ that satisfy the conditions $\sum_{j=1}^{5} x_{i j}=1$, for all $i, x_{i j}=0,1$, for all $i$ and $j$, and the two parties gain the same, i.e., their ratios are equal.

A given solution has benefits/costs ratios that are different for the parties. For example, in Table 5 we give a solution. In this solution, the recruiter has a lower benefits/costs ratio than the candidate, so the recruiter will try to change to another solution where he will get a greater benefits/costs ratio. Table 6 shows the solution in matrix form. 
IS AHP How to write a contact with the AHP. To be submitted to the International Symposium of the Analytic Hierarchy Process, 2016, London U.K.

Table 3. Intensities and the benefits/costs accrued by the recruiter and the employee

\begin{tabular}{|c|c|c|c|}
\hline & INTENSITY & RECRUITER & CANDIDATE \\
\hline \multirow[t]{5}{*}{ SIGNING BONUS (SB) } & $10 \%$ & 0 & 4000 \\
\hline & $8 \%$ & 1000 & 3000 \\
\hline & $6 \%$ & 2000 & 2000 \\
\hline & $4 \%$ & 3000 & 1000 \\
\hline & $2 \%$ & 4000 & 0 \\
\hline \multirow[t]{5}{*}{ SALARY (S) } & $60,000.00$ & -6000 & \\
\hline & $58,000.00$ & -4500 & -1500 \\
\hline & $56,000.00$ & -3000 & -3000 \\
\hline & $54,000.00$ & -1500 & -4500 \\
\hline & $52,000.00$ & 0 & -6000 \\
\hline \multirow[t]{5}{*}{ JOB ASSIGNMENT (JA) } & Division A & 0 & 0 \\
\hline & Division B & -600 & -600 \\
\hline & Division C & -1200 & -1200 \\
\hline & Division D & -1800 & -1800 \\
\hline & Division E & -2400 & -2400 \\
\hline \multirow[t]{5}{*}{ COMPANY CAR (CC) } & LUX EX2 & 1200 & 1200 \\
\hline & MOD 250 & 900 & 900 \\
\hline & RAND XTR & 600 & 600 \\
\hline & DEPAS 450 & 300 & 300 \\
\hline & PALO LSR & 0 & 0 \\
\hline \multirow[t]{5}{*}{ STARTING DATE(SD) } & 1-Jun & 1600 & \\
\hline & 15-Jun & 1200 & 1000 \\
\hline & 1-Jul & 800 & 2000 \\
\hline & 15-Jul & 400 & 3000 \\
\hline & 1-Aug & 0 & 4000 \\
\hline \multirow[t]{5}{*}{ VACATION DAYS (VD) } & 30 days & 0 & 1600 \\
\hline & 25 days & 1000 & 1200 \\
\hline & 20 days & 2000 & 800 \\
\hline & 15 days & 3000 & 400 \\
\hline & 10 days & 4000 & 0 \\
\hline MOVING EXPENSES & $100 \%$ & 0 & 3200 \\
\hline \multirow[t]{4}{*}{ REIMBURSEMENT (MER) } & $90 \%$ & 200 & 2400 \\
\hline & $80 \%$ & 400 & 1600 \\
\hline & $70 \%$ & 600 & 800 \\
\hline & $60 \%$ & 800 & 0 \\
\hline \multirow[t]{5}{*}{ INSURANCE COVERAGE(IC) } & Allen Insurance & 0 & 800 \\
\hline & ABC Insurance & 800 & 600 \\
\hline & Good Health Insurance & 1600 & 400 \\
\hline & Best Insurance Co. & 2400 & 200 \\
\hline & Insure Alba & 3200 & 0 \\
\hline
\end{tabular}


IS AHP How to write a contact with the AHP. To be submitted to the International Symposium of the Analytic Hierarchy Process, 2016, London U.K.

Table 4. Priorities of dimensions and relative scales for the recruiter - candidate case

\begin{tabular}{|c|c|c|c|c|c|c|c|c|}
\hline & & & & & & \multicolumn{3}{|c|}{ Relative Scales } \\
\hline \multicolumn{2}{|c|}{ RECRUITER PRIORITIES } & \multicolumn{2}{|c|}{ CANDIDATE PRIORITIES } & \multirow[t]{2}{*}{ Dimensions } & \multirow[t]{2}{*}{ RECRUITER } & \multirow[t]{2}{*}{ CANDIDATE } & \multirow[t]{2}{*}{ RECRUITER } & \multirow[t]{2}{*}{ CANDIDATE } \\
\hline Benefits & Costs & Benefits & Costs & & & & & \\
\hline \multirow[t]{18}{*}{0.27027018} & & 0.2702701 & & SIGNING BONUS & & & & \\
\hline & & & & $10 \%$ & 0.01 & 4,000 & $1 \mathrm{E}-06$ & 0.3999996 \\
\hline & & & & $8 \%$ & 1,000 & 3,000 & 0.0999999 & 0.2999997 \\
\hline & & & & $6 \%$ & 2,000 & 2,000 & 0.1999998 & 0.1999998 \\
\hline & & & & $4 \%$ & 3,000 & 1000 & 0.2999997 & 0.0999999 \\
\hline & & & & $2 \%$ & 4,000 & 0.01 & 0.3999996 & $1 \mathrm{E}-06$ \\
\hline & 0.714285918 & & 0.714285918 & 8 SALARY & 10000.01 & 10000.01 & & \\
\hline & & & & $\$ 60,000$ & $-6,000$ & 0.01 & 0.40000027 & $6.6667 \mathrm{E}-07$ \\
\hline & & & & $\$ 58,000$ & $-4,500$ & $-1,500$ & 0.3000002 & 0.10000007 \\
\hline & & & & $\$ 56,000$ & $-3,000$ & $-3,000$ & 0.20000013 & 0.20000013 \\
\hline & & & & $\$ 54,000$ & $-1,500$ & $-4,500$ & 0.10000007 & 0.3000002 \\
\hline & & & & $\$ 52,000$ & 0.01 & $-6,000$ & $6.6667 \mathrm{E}-07$ & 0.40000027 \\
\hline & 0.285714082 & & 0.285714082 & JOB ASSIGNMENT & -14999.99 & -14999.99 & & \\
\hline & & & & Division A & 0.01 & 0.01 & $1.6667 \mathrm{E}-06$ & $1.6667 \mathrm{E}-06$ \\
\hline & & & & Division B & -600 & -600 & 0.10000017 & 0.10000017 \\
\hline & & & & Division C & $-1,200$ & $-1,200$ & 0.20000033 & 0.20000033 \\
\hline & & & & Division D & $-1,800$ & $-1,800$ & 0.3000005 & 0.3000005 \\
\hline & & & & Division $\mathrm{E}$ & $-2,400$ & $-2,400$ & 0.40000067 & 0.40000067 \\
\hline \multirow[t]{6}{*}{0.08108124} & & 0.08108122 & & COMPANY CAR & -5999.99 & -5999.99 & & \\
\hline & & & & LUX EX2 & 1200 & 1200 & 0.39999867 & 0.39999867 \\
\hline & & & & MOD 250 & 900 & 900 & 0.299999 & 0.299999 \\
\hline & & & & RAND XTR & 600 & 600 & 0.19999933 & 0.19999933 \\
\hline & & & & DE PAS 450 & 300 & 300 & 0.09999967 & 0.09999967 \\
\hline & & & & PALO LSR & 0.01 & 0.01 & $3.3333 \mathrm{E}-06$ & $3.3333 \mathrm{E}-06$ \\
\hline \multirow[t]{6}{*}{0.10810823} & & 0.2702701 & & STARTING DATE & 3000.01 & 3000.01 & & \\
\hline & & & & 1-Jun & 1,600 & 0.01 & 0.399999 & $1 \mathrm{E}-06$ \\
\hline & & & & 15-Jun & 1,200 & 1,000 & 0.29999925 & 0.0999999 \\
\hline & & & & 1-Jul & 800 & 2,000 & 0.1999995 & 0.1999998 \\
\hline & & & & 15-Jul & 400 & 3,000 & 0.09999975 & 0.2999997 \\
\hline & & & & 1-Aug & 0.01 & 4,000 & $2.5 \mathrm{E}-06$ & 0.3999996 \\
\hline \multirow[t]{7}{*}{0.27026991} & & 0.1081082 & & VACATION DAYS & 4000.01 & 10000.01 & & \\
\hline & & & & 30 days & 0 & 1,600 & 0 & 0.399999 \\
\hline & & & & 25 days & 1,000 & 1,200 & 0.1 & 0.29999925 \\
\hline & & & & 20 days & 2,000 & 800 & 0.2 & 0.1999995 \\
\hline & & & & 15 days & 3,000 & 400 & 0.3 & 0.09999975 \\
\hline & & & & 10 days & 4,000 & 0.01 & 0.4 & $2.5 \mathrm{E}-06$ \\
\hline & & & & MOVING EXPENSES & 10000 & 4000.01 & & \\
\hline \multirow[t]{6}{*}{0.05405425} & & 0.21621614 & & REIMBURSEMENT & & & & \\
\hline & & & & $100 \%$ & 0.01 & 3,200 & $5 E-06$ & 0.3999995 \\
\hline & & & & $90 \%$ & 200 & 2,400 & 0.0999995 & 0.29999963 \\
\hline & & & & $80 \%$ & 400 & 1,600 & 0.199999 & 0.19999975 \\
\hline & & & & $70 \%$ & 600 & 800 & 0.2999985 & 0.09999988 \\
\hline & & & & $60 \%$ & 800 & 0.01 & 0.399998 & $\quad 1.25 \mathrm{E}-06$ \\
\hline \multirow[t]{7}{*}{0.21621619} & & 0.05405424 & & INSURANCE COVERAGE & 2000.01 & 8000.01 & & \\
\hline & & & & Allen Insurance & 0.01 & 800 & $1.25 \mathrm{E}-06$ & 0.399998 \\
\hline & & & & $A B C$ Insurance & 800 & 600 & 0.09999988 & 0.2999985 \\
\hline & & & & Good Health Insurance & 1,600 & 400 & 0.19999975 & 0.199999 \\
\hline & & & & Best Insurance Co. & 2,400 & 200 & 0.29999963 & 0.0999995 \\
\hline & & & & Insure Alba & 3,200 & 0.01 & 0.3999995 & $5 E-06$ \\
\hline & & & & & 8000.01 & 2000.01 & & \\
\hline
\end{tabular}


IS AHP How to write a contact with the AHP. To be submitted to the International Symposium of the Analytic Hierarchy Process, 2016, London U.K.

Table 5. A solution with the Benefit/Cost Ratios

\begin{tabular}{|c|c|c|c|c|c|c|c|c|c|}
\hline \multicolumn{2}{|c|}{ A Solution } & \multicolumn{3}{|c|}{ Intensities } & & \multicolumn{2}{|c|}{ Recruiter } & \multicolumn{2}{|c|}{ Candidate } \\
\hline & 1 & 2 & 3 & 4 & & 5 Benefits & Costs & Benefits & Costs \\
\hline SB & 0 & 0 & 1 & 0 & 0 & \begin{tabular}{l|l|}
0 & 0.135135 \\
\end{tabular} & 0 & 0.135135 & 0 \\
\hline$S$ & 0 & 1 & 0 & 0 & & 0 & 0.535714 & 0 & 0.178571 \\
\hline$J A$ & 0 & 1 & 0 & 0 & & 0 & 0.071429 & 0 & 0.071429 \\
\hline CC & 1 & 0 & 0 & 0 & & 0.081081 & 0 & 0.081081 & 0 \\
\hline SD & 0 & 0 & 1 & 0 & & 0.054054 & 0 & 0.135135 & 0 \\
\hline VD & 0 & 1 & 0 & 0 & & 0.067568 & 0 & 0.081081 & 0 \\
\hline MER & 0 & 0 & 1 & 0 & & $\begin{array}{lll}0 & 0.027027 \\
\end{array}$ & 0 & 0.108108 & 0 \\
\hline IC & 0 & 0 & 1 & 0 & & \begin{tabular}{|l|l|}
0 & 0.108108 \\
\end{tabular} & 0 & 0.027027 & 0 \\
\hline & & & & & & & & & \\
\hline & & & & & B/C Ratio & 0.7790 & & 2.2703 & \\
\hline
\end{tabular}

Table 6. The Optimal Solution

\begin{tabular}{|c|c|c|c|c|c|c|c|c|c|}
\hline \multicolumn{2}{|c|}{ Optimal Solution } & \multicolumn{3}{|c|}{ Intensities } & & \multicolumn{2}{|c|}{ Recruiter } & \multicolumn{2}{|c|}{ Candidate } \\
\hline & 1 & 2 & 3 & 4 & 5 & Benefits & Costs & Benefits & Costs \\
\hline SB & 0 & 0 & 1 & 0 & 0 & 0.135135 & 0 & 0.135135 & 0 \\
\hline S & 0 & & 1 & 0 & 0 & 0 & 0.357143 & 0 & 0.357143 \\
\hline$J A$ & 1 & 0 & 0 & 0 & 0 & 0 & $\begin{array}{r}0 \\
\end{array}$ & $\begin{array}{r}0 \\
\end{array}$ & 0 \\
\hline $\mathrm{CC}$ & 1 & 0 & 0 & 0 & 0 & 0.081081 & 0 & 0.081081 & 0 \\
\hline SD & 0 & 0 & 0 & 0 & 1 & 0 & 0 & 0.27027 & $\underline{0}$ \\
\hline VD & 0 & 0 & 0 & 0 & 1 & 0.27027 & 0 & 0 & 0 \\
\hline MER & 1 & 0 & 0 & 0 & 0 & 0 & 0 & 0.216216 & $\underline{0}$ \\
\hline IC & 0 & 0 & 0 & 0 & 1 & 0.216216 & 0 & 0 & $\underline{0}$ \\
\hline & & & & & & & & & \\
\hline & & & & & B/C Ratio & 1.9676 & & 1.9676 & \\
\hline
\end{tabular}

Translated into the original scale values of the dimensions we have Table 7 . Note that now both the recruiter and the candidate gain the same.

Table 7. The Terms of the Contract

\begin{tabular}{|l|r|r|r|r|r|r|r|r|r|}
\cline { 2 - 10 } \multicolumn{1}{l|}{} & \multicolumn{1}{c|}{ SB } & \multicolumn{1}{c|}{ S } & \multicolumn{1}{c|}{ JA } & \multicolumn{1}{c|}{ CC } & SD & VD & MER & IC & Total \\
\cline { 2 - 9 } & $6 \%$ & $\$ 56,000.00$ & Division A & LUX EX2 & 1 -Aug & 10 days & $100 \%$ & Insure Alba & Points \\
\hline Recruiter & 2000 & -3000 & 0 & 1200 & 0 & 4000 & 0 & 3200 & 7400 \\
\hline Candidate & 2000 & -3000 & 0 & 1200 & 4000 & 0 & 3200 & 0 & 7400 \\
\hline
\end{tabular}

Obviously, the scales within each dimension do not have to be linear. For example, if the recruiter and the candidate have relative intensities as given in Table 8 , the solution 
IS AHP How to write a contact with the AHP. To be submitted to the International Symposium of the Analytic Hierarchy Process, 2016, London U.K.

(Table 9) would not be the same as the one in Table 7. The solutions in Table 9 are within $3.125 \%$ of each other. No other closer solutions exist.

Table 8. Intensities with Non-Linear Relative Scales

\begin{tabular}{|c|c|c|c|c|}
\hline & & & Relative Sca & ales \\
\hline Dimensions & RECRUITER & CANDIDATE & RECRUITER & CANDIDATE \\
\hline & & & & \\
\hline \multicolumn{5}{|l|}{ SIGNING BONUS } \\
\hline $10 \%$ & 0.01 & 4,000 & $1 \mathrm{E}-06$ & 1 \\
\hline $8 \%$ & 1,000 & 3,000 & 0.1 & 0.75 \\
\hline $6 \%$ & 2,000 & 2,000 & 0.5 & 0.5 \\
\hline $4 \%$ & 3,000 & 1000 & 0.9 & 0.1 \\
\hline $2 \%$ & 4,000 & 0.01 & 1 & $1 \mathrm{E}-06$ \\
\hline SALARY & 10000.01 & 10000.01 & & \\
\hline$\$ 60,000$ & $-6,000$ & 0.01 & 1 & $1 E-06$ \\
\hline$\$ 58,000$ & $-4,500$ & $-1,500$ & 0.75 & 0.1 \\
\hline$\$ 56,000$ & $-3,000$ & $-3,000$ & 0.5 & 0.5 \\
\hline$\$ 54,000$ & $-1,500$ & $-4,500$ & 0.1 & 0.9 \\
\hline$\$ 52,000$ & 0.01 & $-6,000$ & $1 \mathrm{E}-06$ & 1 \\
\hline JOB ASSIGNMENT & -14999.99 & -14999.99 & & \\
\hline Division A & 0.01 & 0.01 & $1 \mathrm{E}-06$ & $1 \mathrm{E}-06$ \\
\hline Division B & -600 & -600 & 0.1 & 0.1 \\
\hline Division C & $-1,200$ & $-1,200$ & 0.5 & 0.5 \\
\hline Division D & $-1,800$ & $-1,800$ & 0.9 & 0.9 \\
\hline Division $\mathrm{E}$ & $-2,400$ & $-2,400$ & 1 & 1 \\
\hline COMPANY CAR & -5999.99 & -5999.99 & & \\
\hline LUX EX2 & 1200 & 1200 & 1 & 1 \\
\hline MOD 250 & 900 & 900 & 0.75 & 0.75 \\
\hline RAND XTR & 600 & 600 & 0.5 & 0.5 \\
\hline DE PAS 450 & 300 & 300 & 0.1 & 0.1 \\
\hline PALO LSR & 0.01 & 0.01 & $1 \mathrm{E}-06$ & $1 \mathrm{E}-06$ \\
\hline STARTING DATE & 3000.01 & 3000.01 & & \\
\hline 1-Jun & 1,600 & 0.01 & 1 & $1 \mathrm{E}-06$ \\
\hline 15-Jun & 1,200 & 1,000 & 0.75 & 0.1 \\
\hline 1-Jul & 800 & 2,000 & 0.5 & 0.5 \\
\hline 15-Jul & 400 & 3,000 & 0.1 & 0.9 \\
\hline 1-Aug & 0.01 & 4,000 & $1 \mathrm{E}-06$ & 1 \\
\hline VACATION DAYS & 4000.01 & 10000.01 & & \\
\hline 30 days & 0 & 1,600 & 0 & 1 \\
\hline 25 days & 1,000 & 1,200 & 0.1 & 0.75 \\
\hline 20 days & 2,000 & 800 & 0.5 & 0.5 \\
\hline 15 days & 3,000 & 400 & 0.9 & 0.1 \\
\hline 10 days & 4,000 & 0.01 & 1 & $1 \mathrm{E}-06$ \\
\hline MOVING EXPENSES & 10000 & 4000.01 & & \\
\hline \multicolumn{5}{|l|}{ REIMBURSEMENT } \\
\hline $100 \%$ & 0.01 & 3,200 & 1E-06 & 1 \\
\hline $90 \%$ & 200 & 2,400 & 0.1 & 0.75 \\
\hline $80 \%$ & 400 & 1,600 & 0.5 & 0.5 \\
\hline $70 \%$ & 600 & 800 & 0.9 & 0.1 \\
\hline $60 \%$ & 800 & 0.01 & 1 & $1 \mathrm{E}-06$ \\
\hline INSURANCE COVERAGE & 2000.01 & 8000.01 & & \\
\hline Allen Insurance & 0.01 & 800 & $1 \mathrm{E}-06$ & 1 \\
\hline$A B C$ Insurance & 800 & 600 & 0.1 & 0.75 \\
\hline Good Health Insurance & 1,600 & 400 & 0.5 & 0.5 \\
\hline Best Insurance Co. & 2,400 & 200 & 0.9 & 0.1 \\
\hline \multirow[t]{2}{*}{ Insure Alba } & 3,200 & 0.01 & 1 & $1 \mathrm{E}-06$ \\
\hline & 8000.01 & 2000.01 & & \\
\hline
\end{tabular}


IS AHP How to write a contact with the AHP. To be submitted to the International Symposium of the Analytic Hierarchy Process, 2016, London U.K.

Table 9. Terms of the Contract for the Non-Linear Intensity Case

\begin{tabular}{|c|c|c|c|c|c|c|c|c|c|}
\hline & SB & $\mathrm{S}$ & JA & $\mathrm{CC}$ & SD & VD & MER & IC & Total \\
\hline & $10 \%$ & $\$ 56,000.00$ & Division A & LUX EX2 & 1-Jul & 10 days & \begin{tabular}{|l|}
$90 \%$ \\
\end{tabular} & Insure Alba & Points \\
\hline Recruiter & 0 & -3000 & 0 & 1200 & 800 & 4000 & 200 & 3200 & 6400 \\
\hline Candidate & 4000 & -3000 & 0 & 1200 & 2000 & 0 & 2400 & 0 & 6600 \\
\hline
\end{tabular}

\section{The General Contract Model}

In many contract negotiations, the parties not always act in good faith or share information with the other party. In this case, one should also consider the perceptions of the parties about the benefits and costs of the tradeoffs. For example, in a merger transaction, the buyer (A) and the seller (B) may not always agree as to the terms of the merger, and hence the transaction fails. The steps to make tradeoffs in this more general situation are as follows:

1. Identify the dimensions of the problem

2. Identify the tradeoffs of each party within the dimensions

3. Identify the benefits accrued by a party from the other party's tradeoffs

4. Identify the costs incurred by a party from its own tradeoffs

5. Identify the perceived benefits that the other party received from your tradeoffs

6. Identify the perceived costs incurred by the other party from their tradeoffs

7. Find out what tradeoff each party must make to maximize the total minimum gain they obtain, ensuring that what each party gains is as close as possible to the other party gains. This is what makes the final contract equitable and balanced.

The mathematical model that helps identify the proper contract is given below.

Let $X_{k}(x)$ the scale of the $k$ th dimension. The parties will negotiate on the value of that scale according to their preferences. The realized value of the scale is determined by the benefit, the cost, the perceived benefit and the perceived cost that that value has for each party.

Let $B_{i}\left(x_{k}\right)$ be the benefits accrued by party $i$ from the other party tradeoffs in dimension $k$. Let $C_{i}\left(x_{k}\right)$ be the costs incurred by party $i$ from its own tradeoffs in dimension $k$. Let $P B_{i}\left(x_{k}\right)$ be the benefits party $i$ perceives the other party receives from its tradeoffs in dimension $k$, and let $P C_{i}\left(x_{k}\right)$ be the costs the other party perceives that party $i$ incurs from its tradeoffs in dimension $k$. Thus, for a given dimension $k$, the gain of party $i$ is 
given by the benefits it accrues from the tradeoffs of the other party in that dimension times the costs it perceives the other party incurs in that dimension, i.e., $B_{i}\left(x_{k}\right) P C_{i}\left(x_{k}\right)$. Similarly, the loss in a given dimension $k$ is given by $C_{i}\left(x_{k}\right) P B_{i}\left(x_{k}\right)$. Thus, the gain to loss ratio for a party for a given dimension $k$ is given by:

$$
\frac{B_{i}\left(x_{k}\right) P C_{i}\left(x_{k}\right)}{C_{i}\left(x_{k}\right) P B_{i}\left(x_{k}\right)}
$$

and the total gain-to-loss ratio for a party is given by

$$
r_{i} \equiv \sum_{\text {all } k} \frac{B_{i}\left(x_{k}\right) P C_{i}\left(x_{k}\right)}{C_{i}\left(x_{k}\right) P B_{i}\left(x_{k}\right)}
$$

Let $x_{k}(s)$ be a binary variable, where $x_{k}(s)=1$ if the parties agree on selecting the intensity $s$ of the $k$ th dimension as the best decision for both of them. The problem now consists in finding values of $s$ for each dimension that maximizes the smallest gain-toloss ratio of both parties, i.e.,

$$
\underset{s}{\operatorname{Max}}\left\{\operatorname{Min}\left\{r_{i}(s) \equiv \sum_{\text {all } k} \frac{B_{i}\left[x_{k}(s)\right] P C_{i}\left[x_{k}(s)\right]}{C_{i}\left[x_{k}(s)\right] P B_{i}\left[x_{k}(s)\right]}, r_{j}(s) \equiv \frac{B_{j}\left[x_{k}(s)\right] P C_{j}\left[x_{k}(s)\right]}{C_{j}\left[x_{k}(s)\right] P B_{j}\left[x_{k}(s)\right]}\right\}\right\}
$$

Subject to $\sum_{s} x_{k}(s)=1$ and $\left|1-\frac{r_{i}(s)}{r_{j}(s)}\right| \leq \varepsilon$, where $\varepsilon$ is the tolerance that measures how far the two parties are in terms of their total gain-to-loss ratio.

\section{Conclusions}

The main difference between this approach and that used in the analysis of the Palestinian-Israeli conflict (Saaty and Zoffer 2011; 2013) is that the tradeoffs were analyzed in pairs. In the case of a contract, the scales in which the dimensions are measured makes it impossible to analyze all possible pairs of tradeoffs. For example, in the simple case given above, the number of tradeoffs is $2^{8 \times 4}=4,294,967,296$. Thus, we use a non-linear optimization model, albeit it is also a MaxMin model. 
IS AHP How to write a contact with the AHP. To be submitted to the International Symposium of the Analytic Hierarchy Process, 2016, London U.K.

\section{References}

Fisher, R. and W. Ury (1981). Getting to YES: Negotiating Agreement Without Giving In. New York, Penguin Books.

Saaty, T. L. and H. J. Zoffer (2011). "Negotiating the Israeli Palestinian Controversy from a New Perspective." International Journal of Information Technology and Decision Making 10(1): 5-64

Saaty, T. L. and H. J. Zoffer (2013). "Principles for Implementing a Potential Solution to the Middle East Conflict." Notices of the American Mathematical Society 60(10): $1300-1322$ 